\title{
Assessment of Interventions by Pharmacist in Improving Knowledge, Attitude and Practice towards Hypothyroidism among the Patients Attending at an Endocrine Clinic in Nepal
}

\author{
Sushma Maharjan* and Himal Paudel Chhetri \\ Department of Pharmacy, Kathmandu University, Dhulikhel, Nepal.
}

\begin{abstract}
Background: The diverse role of pharmacist for management of chronic disease carries significant effects. Hypothyroidism, common chronic endocrine disorders can affect multiple organs. So, educating patient can bring fluorescent in management of chronic disease like hypothyroidism. This study assessed the pharmacist provided intervention in hypothyroid patients in terms of knowledge, attitude and practice outcomes. Method: A prospective, case controlled, interventional based study with total 118 patients diagnosed with hypothyroid condition as the inclusion criteria. Knowledge, attitude and practice regarding hypothyroidism were assessed and recorded by using appropriately designed and validated standard questionnaire. Test group patients were counseled regarding hypothyroidism and provided with informative leaflet to them in local (Nepali) language. While in control group patients, no intervention was provided by pharmacist. After one month interval, knowledge, attitude and practice score were measured in both groups (test and control) by using same knowledge, attitude and Practice questionnaire. Effectiveness of counseling was evaluated in the test group by comparing mean scores of knowledge, attitude and practice before and after intervention using sampled paired t-test. Results: Mean knowledge, attitude and practice score of test group patients before intervention were $5.290 \pm 3.043$, $14.709 \pm 1.540$ and $2.677 \pm 0.471$ respectively and after intervention the score were $7.935 \pm 2.231,15 \pm$ 1.201 and $2.935 \pm 0.247$ respectively ( $p$ value $<0.05)$. Conclusion: Positive impact on patient's knowledge, attitude and practice towards disease management after intervention by pharmacist was observed.
\end{abstract}

Key words: Attitude, Hypothyroidism, Knowledge, Practice score.

\section{INTRODUCTION}

Globally the patient with hypothyroidism is $1-10 \%$ and is one of the common disorders seenin women older than 60 years. ${ }^{1}$ about 300 million of population areaffected with thyroid dysfunction where as more than half are unaware about their condition. In Nepal, thyroid dysfunction is one of the major problems prevalent about $30 \%$ in eastern region. Hypothyroidism is common thyroid dysfunction and its prevalence and pattern depends on socio-demographic, geographic and environmental factors. ${ }^{2}$ It is a common chronic disorder and defined as the thyroid gland cannot produce enough thyroid hormone, keep the body running normally. ${ }^{3}$ It has different etiologies and clinical manifestations. Appropriate treatment requires an accurate diagnosis and is influenced by co-morbidities. Hence, Fiftytwo evidence-based recommendations were found to aid in the care of patients with hypothyroidism. The standard treatment is levothyroxine replacement therapy. ${ }^{4}$ Though hormone replacement therapy is not so expensive, under and over treatment is common among them and profound effects on various organs such as cardiovascular system, endocrine system, nervous system and brain is seen. So, education regarding hypothyroidism is a crucial step and requires a
Submitted date :28/02/2015 Accepted date : 10/06/2015

DOI: 10.5530/ijopp.8.2.4

Address for correspondence: Dr. Sushma Maharjan, Department of Pharmacy, Kathmandu University, Dhulikhel,Nepal.

E-mail:maharjan.sushma@ gmail.com

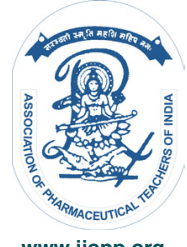


health care team to provide the patient with the best care in which the pharmacist can play a key role.

Pharmacist's role is changed significantly above the past 30 years. Traditionally, the role of pharmacists is dispensing and compounding medication. The concept of pharmacy practice is changed gradually till now from a product oriented activity to a patient-oriented one. Pharmacists' job is extended from dispensing to monitoring drug therapy in clinical settings. ${ }^{5}$

Better pharmacotherapeutic outcomes can be achieved through better understanding of hypothyroidism and thyroxine replacement therapy via counseling.Improved outcomes can be measured in terms of knowledge, attitude and practice scores. A cross-sectional study conducted in medical college, Meerut revealed that totalof 200 patients with thyroid disorder had poor knowledge and misconception regarding this. Patient education can play vital role for evaluation of knowledge, attitude and practice level among them. ${ }^{6} \mathrm{~S}$ Kannan et al. revealed management of hypothyroidism covered appropriate use of medication, dose adjustment as well as patient education to obtain better outcome. ${ }^{7}$ Similarly, another study carried out at Manipal Teaching hospital in 2006 with total 182 patients, suggested low level of knowledge, attitude and practice can be improved by launching awareness program for the patient. ${ }^{8}$ A study conducted by Anurodh Ghimirey et al. concluded that the patients' knowledge, attitude and practice level towards disease management was improved by pharmacist provided counseling. ${ }^{9}$ Subish Palaian et al. assessed the impact of pharmacist provided intervention in hospitalized patients where pharmacist can educate the patients with chronic disease making strategies to improve patients' knowledge, attitude and practice level. ${ }^{5}$

In Nepal, paucity of awareness programs regarding hypothyroidism like diabetes exists. People are unaware of hypothyroidism because of lack of knowledge about the disorder and medication. Misleading sign and symptoms and ignorant in monitoring thyroid level on regular basis are some common problems observed in hypothyroid patients. Associated trouble with this disorder is delay progression of other medical conditions and worsen the patient's health as well as increases expenses. Patient education play significant role in reduction of their burden.

\section{MATERIAL AND METHODS}

This is prospective, interviewed based, interventional case control study conducted from April 2014 to September 2014, at Diabetes, Thyroid and Endocrinology Care Centre, Kupondole, Lalitpur, Nepal. This institute is a private endocrine clinic providing health services to public with endocrine problems like diabetes, thyroid dysfunction. A total of 118 patients were enrolled in the study, 59 patients diagnosed with hypothyroidism in each group (test and control) as inclusion criteria.

\section{Patient inclusion criteria}

Hypothyroid patients of age range 16-75 years visiting the endocrine clinic as OPD patients were included in the study.

\section{Patient exclusion criteria}

Pregnant women, psychiatric and hospitalized patient with thyroid dysfunction were excluded from the study.

\section{Measurement tools, data collection, data analysis}

The knowledge, attitude, and practice (KAP) questionnaire (in Nepali language)was designed and validated. Validation was done by pretesting among 10 members of a group, collected the responses, analyzed and then rearranged it. Finally self administered questions were provided and data was collected from test and control group.

The answers were analyzed by using following scoring system. Regarding knowledge questions, each correct answer was scored as one (1) and for an incorrect answer was scored as zero (0). Likewise practice questions, adhering to the guidelines for disease management or instructions from the patient's health care provider was merited a score of one (1) while non-adherence was scored as zero (0). Attitude questions were measured by using 5 point Likert scale where the patient level of agreement towards the given statement was checked. Each question was scored as five (5) for the greatest level of agreement (strongly agree), zero (0) for the lowest level of agreement (strongly disagree) and others in between 1 and 5. The total score of the question for each knowledge, attitude and practice was calculated by summing the score obtained from each question and obtained data were analyzed.

The collected data was reviewed and statistically analyzed using Statistical Packaging (SPSS) version 18.0 and Microsoft Excel 2007. The effectiveness of counseling in terms of knowledge, attitude and practice outcomes was measured by comparing the mean KAP scores before and after pharmacist provided intervention using Sampled paired t-test. A p-value of $<0.05$ was considered significant throughout the study.

\section{RESULT}

The study enrolled a total 118 patients of mean age group $41.22 \pm 11.33$ years and age ranging 35 to 45 years and $87.3 \%$ were females and $12.7 \%$ were male as illustrated in Table $1.21 .2 \%$ had history of hypothyroidism in their family members. Occupation data showed that half of them were housewives $(56 \%)$ and few of them were involved in business (5\%). The research 


\begin{tabular}{|ccc|}
\hline \multicolumn{3}{|c|}{ Table 1: Patients demographic attributes } \\
\hline Age & Frequency & Percent \\
\hline $15-25$ & $11 /$ & 9.3 \\
$25-35$ & 24 & 20.3 \\
$35-45$ & 42 & 35.6 \\
$45-55$ & 27 & 22.9 \\
$>55$ & 14 & 11.9 \\
Gender & & \\
Male & 15 & 12.7 \\
Female & 103 & 87.3 \\
\hline
\end{tabular}

\section{Table 2: Comparison of KAP scores of test and control group}

\begin{tabular}{lccc}
\multicolumn{1}{c}{ Test group } & & \\
\hline \multicolumn{1}{c}{ Category } & $\begin{array}{c}\text { Mean scorebefore } \\
\text { intervention }\end{array}$ & $\begin{array}{c}\text { Mean score after } \\
\text { intervention (one } \\
\text { month interval) }\end{array}$ & P-value \\
\hline Knowledge score & $5.2903 \pm 3.04279$ & $7.9355 \pm 2.23145$ & 0.000 \\
Attitude score & $14.7097 \pm 1.54057$ & $15.3548 \pm 1.11762$ & 0.001 \\
Practice score & $2.5484 \pm 0.61876$ & $2.7742 \pm 0.42153$ & 0.018 \\
& Control group & & P-value \\
\hline \multicolumn{1}{c}{ Category } & Mean score at & Mean score after one & 0.812 \\
\hline Knowledge score & $2.7500 \pm 2.34521$ & $2.7679 \pm 2.32763$ & 0.606 \\
Attitude score & $13.2857 \pm 0.9480$ & $13.3393 \pm 0.9587$ & 0.200 \\
Practice score & $2.5536 \pm 0.68542$ & $2.3571 \pm 0.74903$ & \\
\hline
\end{tabular}

revealed 36.4\% were hypothyroid patient with other medical problems like diabetes, hypertension, high cholesterol and migraine. Among them 47.5\% were already diagnosed as hypothyroid patients and $6.8 \%$ were newly diagnosed patients. The clinical manifestation of study subjects were sore throat $(41.60 \%)$, fatigue $(36.40 \%)$, voice change $(36.40 \%)$, neck pain $(22.10 \%)$, constipation $(19.50 \%)$, weight gain $(20.80 \%)$, sleepiness $(15.60 \%)$, cold intolerance $(10.40 \%)$, joint pain $(10.40 \%)$, depression $(9.10 \%)$, hair fall $(9.10 \%)$, irregular menstruation $(6.50 \%)$, difficulty in swallow $(7.80 \%)$, difficulty in breath $(3.90 \%)$ and skin problem $(1.30 \%)$ shown in Figure 1.

The mean baseline knowledge, attitude and practice score of test group were $5.29 \pm 3.042,14.70 \pm 1.54$ and $2.67 \pm 0.47$ respectively. After intervention, knowledge score was $7.93 \pm 2.23$, which was significantly higher ( $\mathrm{p}$ value $<0.05)$ with improved knowledge and the attitude of patients towards hypothyroidism was changed after counseling ( $p$ value $<0.05$ ). Similarly, mean practice score was $2.774 \pm 0.421$ after intervention ( $\mathrm{p}$ value $<0.05$ ) significantly improved the practice of hypothyroid patients, while the mean knowledge, attitude and practice scores of control group were in significant after one month follow up (P-value $>0.05)$ shown in Table 2.

\section{DISCUSSION}

The goal of study was to assess the knowledge, attitude and practice scores of hypothyroid patients following pharmacist provided intervention. Patient education is core key to achieve correct therapeutic outcome and bring vivid change in treatment. ${ }^{10}$ Pharmacist is a foremost person who improves knowledge levelof the patients regarding the drugs through group education and patient counseling. ${ }^{8}$ Improved knowledge shows positive effect on patients' attitude level along with this patient will get better practice. In 2010, Thomas et al. suggested clinical pharmacist improves treatment outcome in term of knowledge, attitude and practice scores of the patients after counseling. ${ }^{11}$ Another study conducted by Sharma et al. concluded improves of knowledge, attitude and practice after providing information regarding disease and medication. ${ }^{12}$

The mean age group of the patients was $41.22 \pm 11.33$ years and age ranged from 35 to 45 years in this study. The result is supported by acase control study that was carried out at the Gandaki Medical College Teaching Hospital (GMCTH) Pokhara, Nepal and the mean age of hypothyroid patients was $42 \pm 13.4$ years. ${ }^{11}$ However, many studies suggested the prevalence of hypothyroidism is higher in elderly in the community. Moreover, another study revealed the hypothyroidism is 


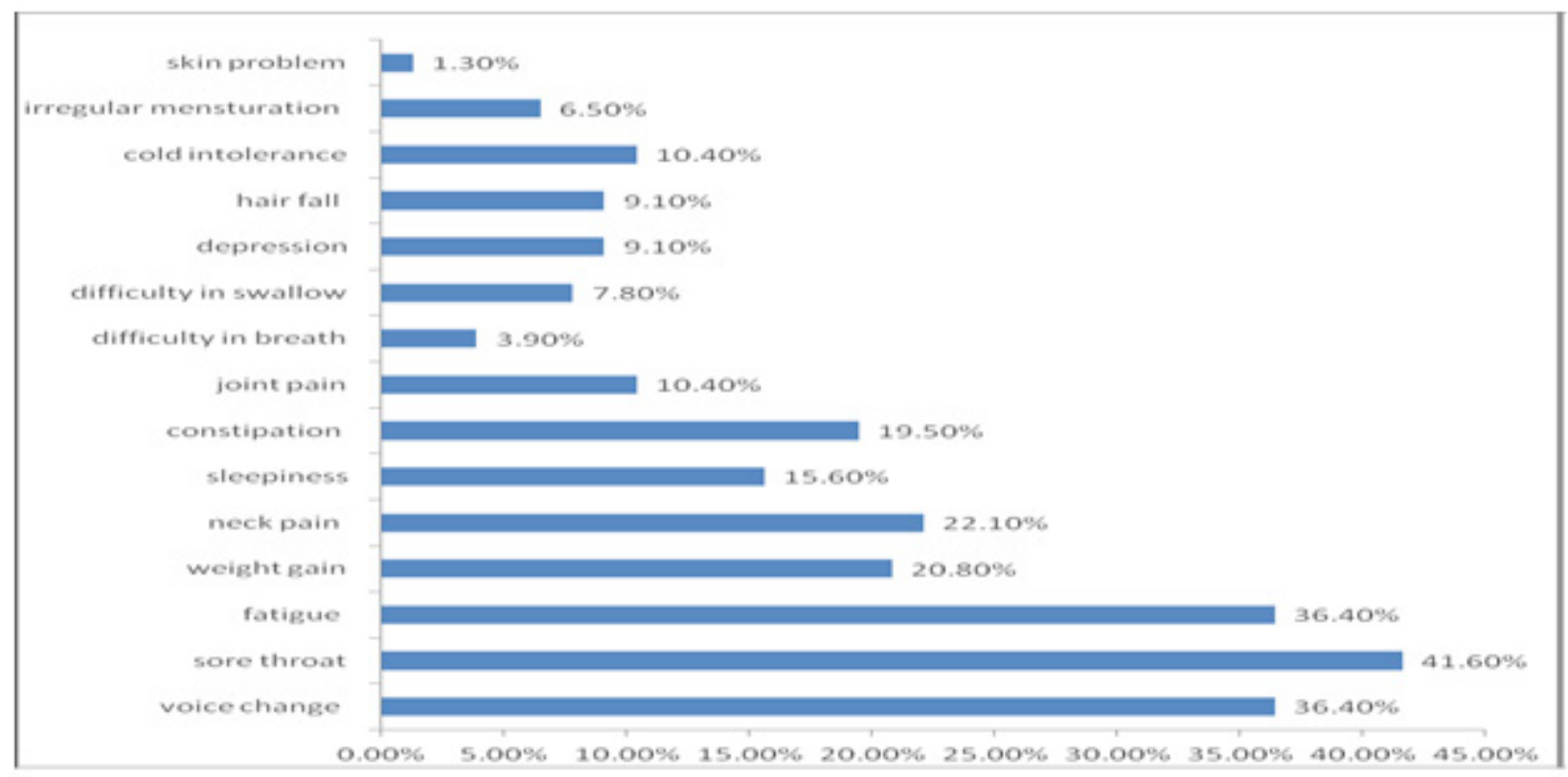

Figure 1: Sign and Symptoms of hypothyroidism

of 5 times greater risk in persons aged $\geq 80$ years compared with those aged 12 to 49 years. ${ }^{13}$ Similarly, a study done in Leiden, Netherlands, overt hypothyroidism was found in 7\% of 558 subjects aged between 85 and 89 year. ${ }^{14}$ Hypothyroidism was commonly seen in female population than in male populationmainly because of effect of female hormonal imbalance. Birth control pills, pregnancy, and postmenopausal estrogen supplementation are used by women, increasing the levels of Thyroxine-binding globulin (TBG) and decreasing the free thyroxine in circulation. While, the male hormone testosterone has no effect on Thyroxine-binding globulin (TBG) and actually stimulates the conversion of the inactive thyroid hormone, T4, to the active thyroid hormone, T3, within the cells. ${ }^{15}$ About half of enrolled subjects were homemaker $(56 \%)$ followed by job holder $(31 \%)$, students $(8 \%)$ and businessman $(5 \%)$.Concerning comorbidities, $36.4 \%$ hypothyroid patientswith other medical problems like diabetes, hypertension, high cholesterol and migraine. The clinical manifestations are varied due to involvement of different organs as shown in Figure 1.

\section{REFERENCES}

1. Kansagra Shayri M, McCudden Christopher R, Willis Monte $S$. The Challenges and Complexities of Thyroid Hormone Replacement. Lab Medicine 2010; 41(6): 338.

2. Arya Madhukar, Gyawal Prabin, RajbhandariNirakar, AryalPratibha, Pandeya Dipendra Raj. A prevalence of thyroid dysfunction in Kathmandu University Hospital, Nepal. Biomedical Research 2010; 21(4): 411-5.

3. Hypothyroidism. http://www.thyroid.org/what-is-hypothyroidism. [Accessed date: 07.21.2014.]

4. ATAIAACE Guideline for hypothyroidism in adults. Endocr pract. 2012; 18(6): 989.

\section{CONCLUSION}

Patient education improved the understanding level of patients towards hypothyroidism. Pharmacist can play a main role in improving patient care by counseling. Hence this study suggested advantages of intervention by pharmacist in improving knowledge attitude and practice of patients towards management of disease.

\section{ACKNOWLEDGEMENTS}

The authors would like to express sincere and heartfelt gratitude to faculty members Kathmandu University pharmacy department and Diabetes, Thyroid and Endocrinological care centre staffs for their priceless contribution throughout study. Authors express profuse gratitude to Dr. Rabindra Kayastha for his incredible assist in the Statistical analysis.

\section{CONFLICT OF INTEREST}

We wish to confirm that there are no known conflicts of interest associated with this publication.
5. Palaian Subish, Acharya Leelavathy D, Rao Padma Guru Madhva, Shankar P, Ravi, Nair Nidin Mohan, et al. Knowledge, Attitude, and Practice Outcomes: Evaluating the Impact of Counseling in Hospitalized Diabetic Patients in India. P\&T 2006; 31(7): 383.

6. Singh Ashutosh, Sachan Beena, Malik Nisha P, Sharma VK, Verma Nidhi, Singh CP. Knowledge, Awareness and Practices (KAP) among Patients with Thyroid Swelling Attending Cytology Clinic in a Medical College, Meerut. Scholars Journal of Applied Medical Sciences 2013; 1(6): 793-5.

7. Kannan S, Mukundan L, Mahadevan S, Sathya A, Kumaravel V, Bhat RV, et al. Knowledge, Awareness and Practices (KAP) among patients with

Indian Journal of Pharmacy Practice, Vol 8, Issue 2, Apr-Jun, 2015 
hypothyroidism attending endocrine clinics of community hospitals in Chennai. Thyroid Research and Practice 2014; 7(1): 11-5.

8. Upadhyay Dinesh K, Palaian Subish, Shankar P, Ravi, Mishra Pranaya. Knowledge, Attitude and Practice about Diabetes among Diabetes Patients in Western Nepal. Rawal Med J. 2008; 33(1): 8-11.

9. Ghimirey et al. Evaluation of pharmacist counseling in improving knowledge, attitude, and practice in chronic kidney disease patients. SAGE Open Medicine 2013 October; 1: 2050312113516111.

10. Hulisz Darrel. Current Challenges in the Management of Hypothyroidism. U.S. Pharmacist 2012 January; 100(10): 13-1678.

11. Thomas Reema, Ramesh Adepu, Thomas Sabin. Impact of clinical pharmacist intervention on knowledge, attitude and practice (KAP) of patients with chronic obstructive pulmonary disease. International Journal of Pharmacy and Pharmaceutical Sciences 2010; 2(4): 54-7.
12. Sharma sushmita, khanalaarati, poudelbharat, sharmaroshani, srivastavsunil, Parajulikalpana, et al. Knowledge, attitude and practice outcomes: an effect of pharmacist provided counseling in hypertensive patients in a tertiary care teaching hospital in western Nepal. Int. J. Ph. Sci. 2010; 2(2): 583.

13. Aoki Y, Belin RM, Clickner R, Jeffries R, Phillips L, Mahaffey KR. Serum TSH and total T4 in the United States population and their association with participant characteristics. National Health and Nutrition Examination Survey (NHANES 1999-2002) 2007; 17(12): 1211-23.

14. Gussekloo J, van Exel E, de Craen AJM, et al. Thyroid status, disability and cognitive function, and survival in old age. JAMA. 2004; 292(21): 2591-9.

15. Hotze Steven F. The Thyroid and Hormone Connection. Hotze Health \& Wellness Center 2007; 17: (www.hotzehwc.com)]. 